Original title / titulo original Rituales altiplánicos y cuzqueños en Atacama, acuerdos i tensiones: el caso de Turi Author(s)/ autor(es):

Carlos Aldunate del Solar

Published originally as/ Publicado originalmente en: Estudios Latinoamericanos, 17, pp. 89-108.

DOI: https://doi.org/10.36447/Estudios1996.v17.art3

Estudios Latinoamericanos is a journal published by the Polish Society for Latin American Studies (Polskie Towarzystwo Studiów Latynoamerykanistycznych).

The Polish Society for Latin American Studies is scholarly organization established to facilitate research on Latin America and to encourage and promote scientific and cultural cooperation between Poland and Latin America.

Estudios Latinoamericanos, revista publicada por la Sociedad Polaca de Estudios Latinoamericanos (Polskie Towarzystwo Studiów Latynoamerykanistycznych).

Sociedad Polaca de Estudios Latinoamericanos es una asociación científica fundada con el fin de desarrollar investigaciones científicas sobre América Latina y participar en la cooperación científica y cultural entre las sociedades de Polonia y América Latina. 


\title{
Rituales altiplánicos y cuzqueños en Atacama, acuerdos y tensiones: el caso de Turi
}

\author{
Carlos Aldunate del $S$.
}

El desierto de Atacama, una enorme extensión de más de $200.000 \mathrm{~km}^{2}$, que se extiende desde la cordillera de Los Andes hasta el Océano Pacífico, se caracteriza por ser uno de los lugares más áridos del planeta. Sólo un río, el Loa, cruza este desierto, y los asentamientos humanos que allí se establecieron lo hicieron en los oasis ubicados en sus riberas, en la precordillera donde nacen cursos de agua que luego desaparecen en el desierto, o en los escasísimos lugares con recursos de agua dulce que existen en la costa. (LÁmina 1)

Desde el punto de vista de la división del área andina propuesta por Lumbreras $^{1}$, el desierto de Atacama está comprendido en el área andina Centro Sur, caracterizada por una fuerte influencia de las sociedades altiplánicas en su desarrollo cultural. Desde este punto de vista, caracterizan a las sociedades que vivieron en estos extensos territorios un Arcaico con indicios de sedentaridad y domesticación de camélidos en sus fases finales; un Formativo o Inicial fuertemente vinculado a tierras altas del altiplano nuclear (Pukara, Qaluyu) y a las vertientes orientales de la cordillera de los Andes (San Francisco, Condorhuasi) y un Período Medio, con la fuerte impronta de Tiwanaku. En el período Intermedio Tardío, toda la región se disgrega políticamente y queda bajo las redes de influencia de los señoríos altiplánicos. Por último, durante el período Tardío, las sociedades de esta área caen bajo la esfera del Tawantinsuyu. (LÁMINA 2) 


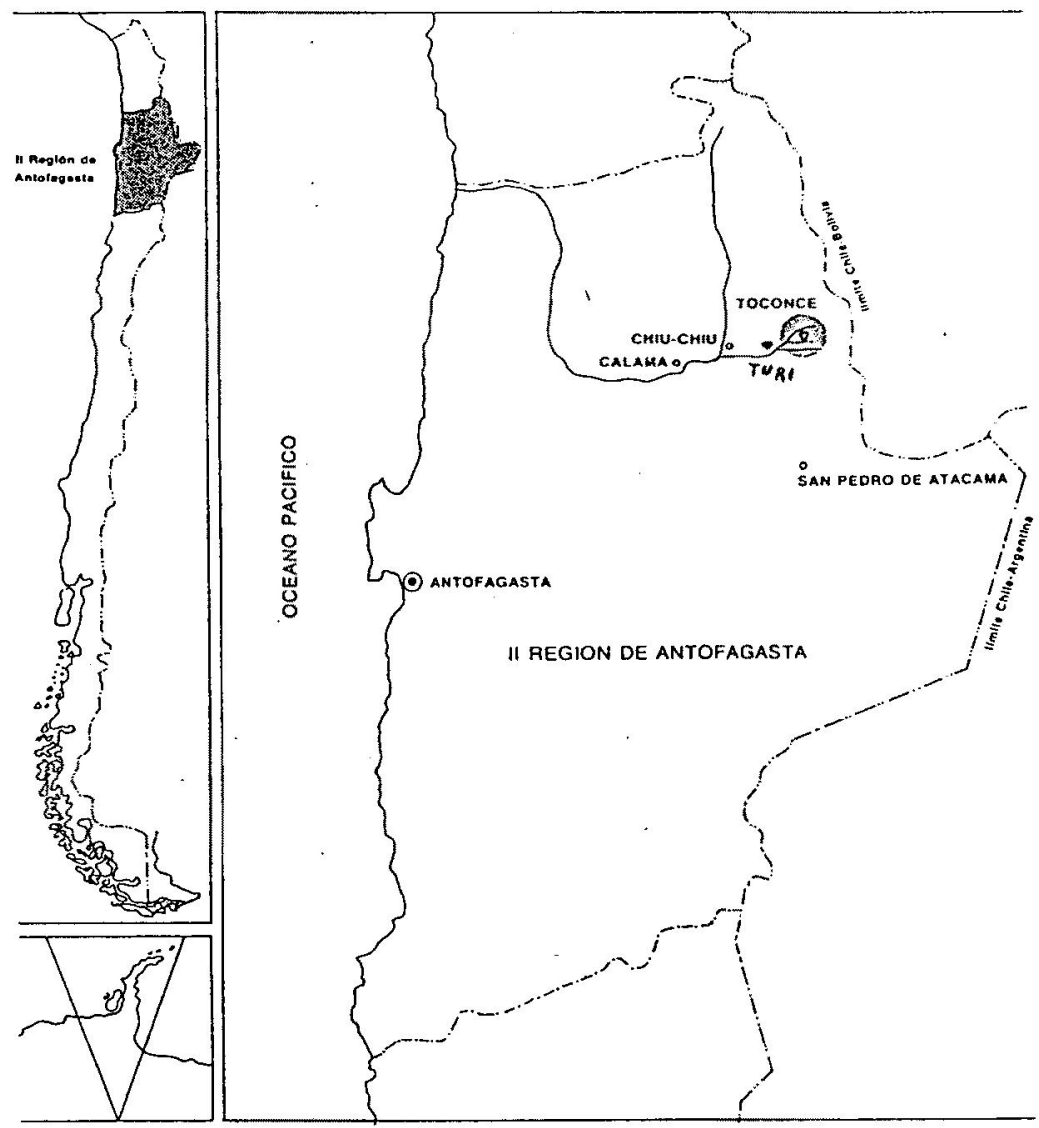

LÁMINA 1 


\section{AREA CENTRO-SUR ANDINA}

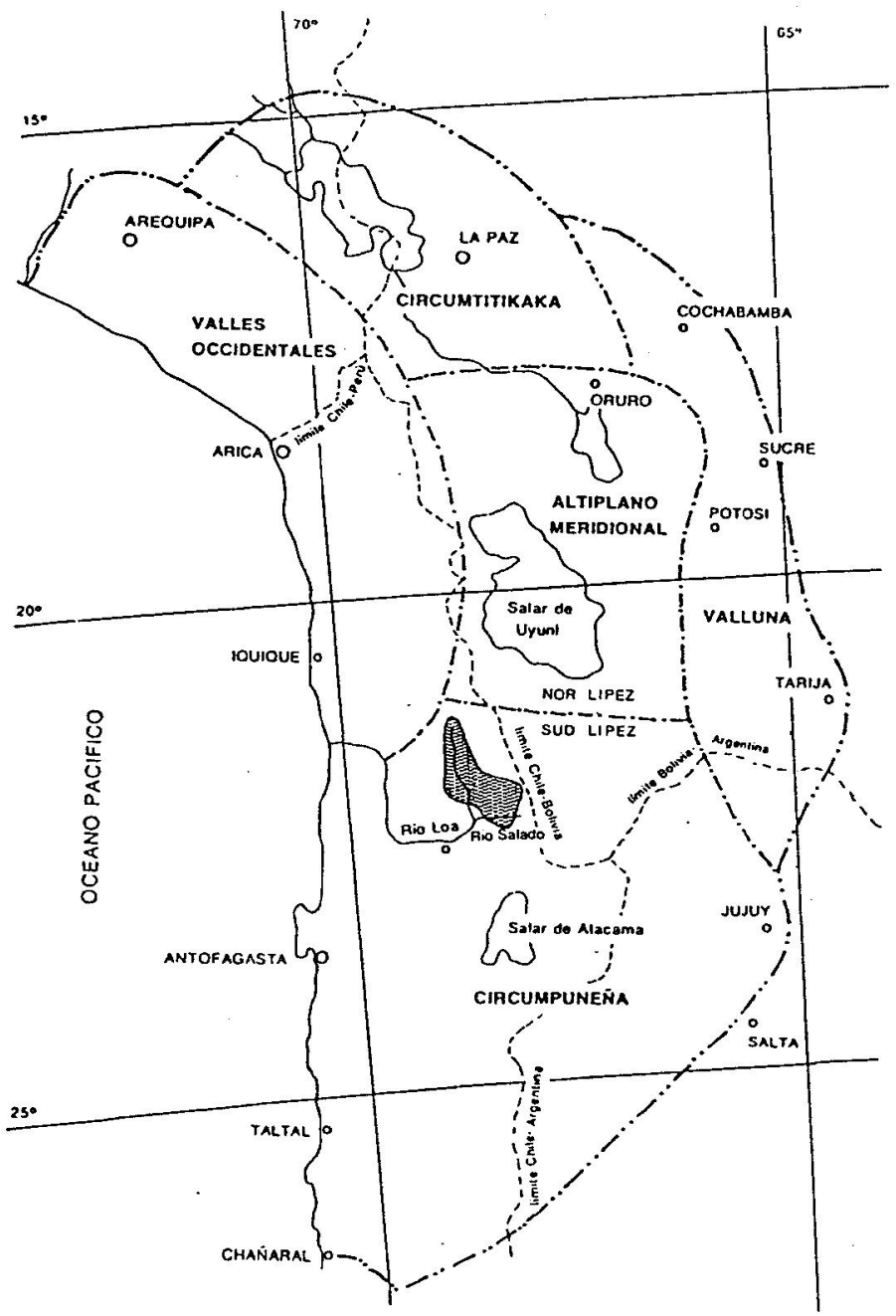

LÁMINA 2 


\section{El sitio de Turi.}

La localidad de Turi está a 3.000 m s.n.m., en las estribaciones orientales del desierto de Atacama y por tanto, se beneficia de las napas y surgencias de agua que escurren de los volcanes y altas cumbres andinas. Ellas son el origen de una gran vega o bofedal, formada por las aguas subterráneas que confluyen a esta planicie desde los planos inclinados que la rodean. La importancia económica y cultural de este rasgo es trascendental para comprender el papel que la localidad desempeñó y aún juega en la vida de las sociedades andinas que todavía la habitan. En efecto, Turi es la única fuente de pastos permanentes de la región con acceso expedito en todas las estaciones de año, ya que las vegas de altura no son accesibles en invierno. Por otra parte, la región sufre frecuentes y largos períodos de sequía, lo que transforma a estas vegas - a pesar de sus actuales magros recursos (Aldunate 1985) - en un recurso insustituible para el mantenimiento y desarrollo de sus economías ganaderas. Las fuentes de alimento de estos bofedales son manantiales que han sido utilizados desde tiempos pretéritos tanto para regar la vega como para mantener plantaciones de diversos productos agrícolas.

Para aprovechar y controlar este recurso, durante el siglo $\mathrm{X}$, comunidades agroganaderas que vivían en el lugar, construyeron en las laderas de un pequeño promontorio que domina el lugar y junto a las fuentes de agua que riegan la vega, una aldea que fue ocupada hasta épocas coloniales bastante avanzadas. Este asentamiento es conocido con el nombre de pukara de Turi.

El pukara de Turi compromete una extensión aproximada de 40.000 metros cuadrados de superficie y está ubicado sobre un montículo que se levanta al Este de las vegas, dominándolas desde su cima. Se trata de una compleja aldea nucleada, en la que se distinguen sectores funerarios, habitacionales, ceremoniales y comunales; muros de circunvalación, calles, caminos, apachetas o hitos marcadores de tráfico y expresiones de arte rupestre. En algunos espacios, especialmente en el sector sur del pukara, se observan ordenamientos espaciales muy claros, como caminos y otras vías de circulación interna; también se encuentran presentes sectores con edificaciones de características homogéneas que han sido evidentemente interrumpidos por construcciones posteriores, todo lo cual sugiere que este pukara no corresponde a una sóla ocupación, sino que su estado actual es el resultado de una larga y compleja historia. (LÁMINA 3) 


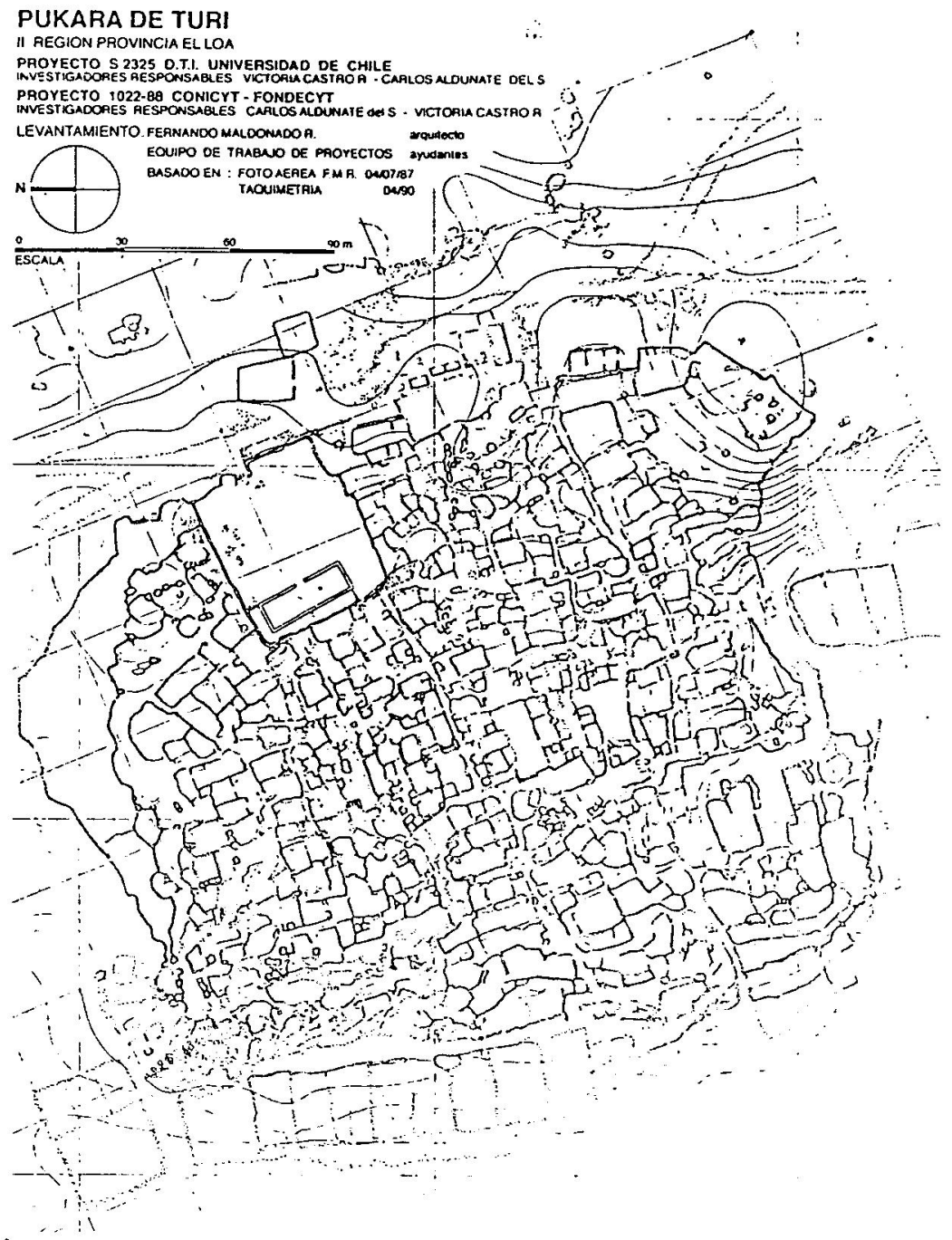

\section{LÁMINA 3}


Las investigaciones arqueológicas realizadas en $\mathrm{Turi}^{2}$, han develado parte de la historia de este asentamiento, y distinguido tres fases en su ocupación. Turi 1 delata la aparición de una aldea nucleada con características locales atacameñas, en los inicios del siglo $\mathrm{X}$ d.C. Posteriormente, durante Turi 2, a mediados del siglo XIV, se produce un mestizaje de esta sociedad con importantes aportes del vecino altiplano, actual región de Lipez. En la segunda mitad del siglo XV, el asentamiento de Turi 2 sufre importantes modificaciones y aparecen estructuras netamente incaicas. Turi 3 corresponde al asentamiento que perdura en épocas coloniales hasta mediados del siglo XVII.

El levantamiento topográfico del pukara, permite distinguir algunos rasgos y configuraciones que resultaron de esta historia y que se deben destacar para los efectos de este trabajo.

El Sector Poniente:

Constituye la parte medular del pukara y se distingue por presentar un ordenamiento complejo. Hay diversas vías de circulación internas, algunas de ellas excelentemente conservadas, marcando claros caminos, que separan a conjuntos de estructuras de patrones semicirculares y algunas rectangulares que se perciben como unidades separadas. Casi todas ellas conservan sus vanos de acceso, que presentan a menudo una estructura complementaria exterior, a modo de paraviento. Algunos de los recintos rectangulares son de grandes proporciones e inscriben a otros de dimensiones menores. En estos sectores, y especialmente en el centro del pukara, se ubica una gran concentración de artefactos de molienda ${ }^{3}$. Un rasgo característico de esta parte del asentamiento, que le imprime un orden espacial deliberadamente marcado, es un camino que cruza el pukara por su parte central, en sentido Oeste-Este y llega hasta la gran plaza de la cumbre.

2. C. Aldun at e: «Arqueología en el pukara de Turi», en: Actas del XII Congreso Nacional de Arqueología Chilena, Temuco 1993; V. Castro: «Arquitectura del Pukara de Turi», en: Actas del XII Congreso de Arqueología Chilena, Temuco 1993; L. Cornejo: «La molienda en el pukara de Turi», en: Actas del XII Congreso de Arqueología Chilena, Temuco 1993; «El inka en la región del río Loa: lo local y lo foráneon, en: 48 Congreso Internacional de Americanistas, Upsala, Suecia 1994, manuscrito de ponencia presentada; F. Gall a rdo: Arquitectura inka y poder en el pukara de Turi, manuscrito en prensa en la "Gaceta Arqueológica Andina», Lima.

3. L. Corne jo: op. cit. 1993. 


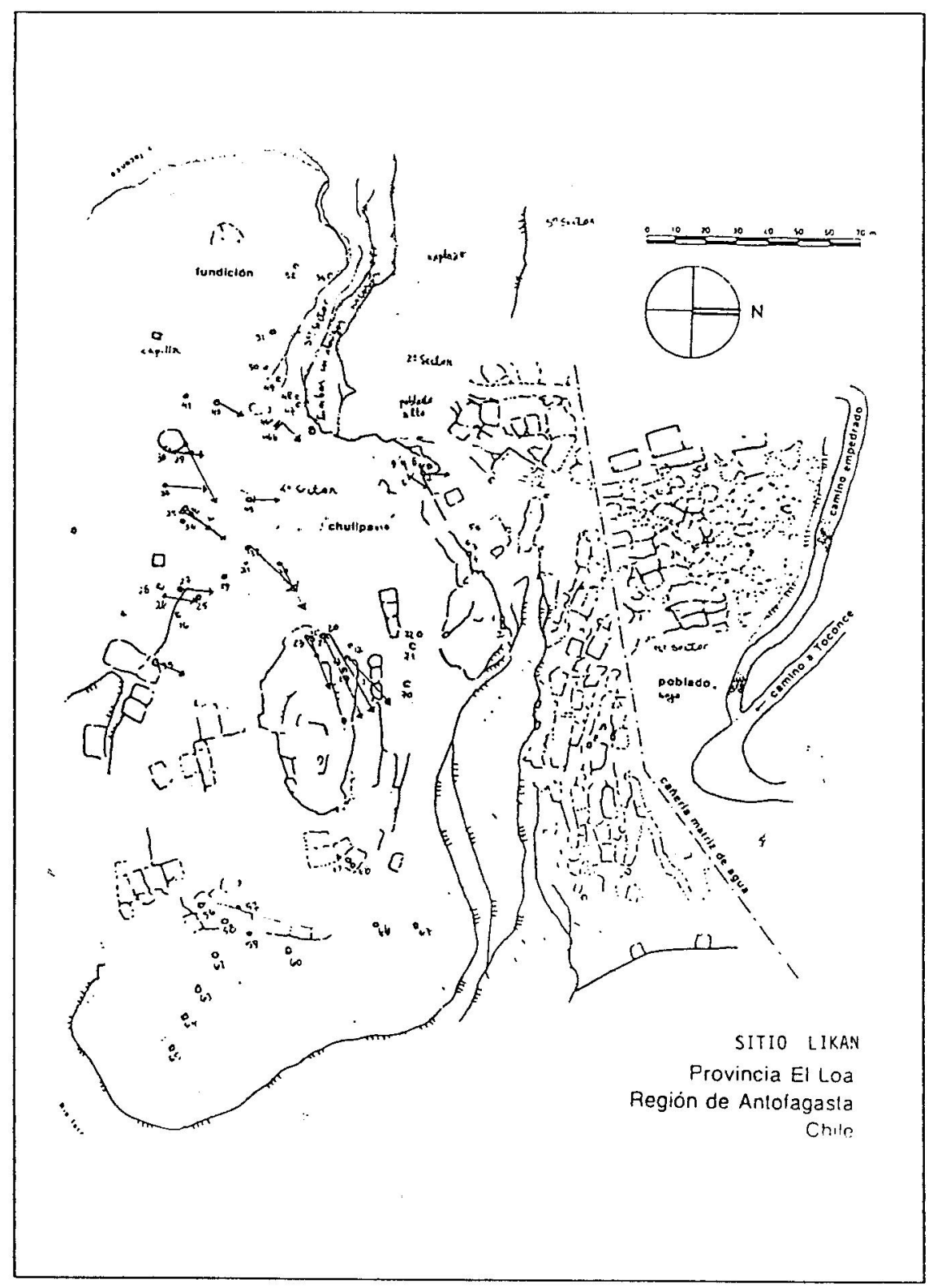

LÁMINA 4 



\section{Sector Oriental:}

Está sobre las partes más altas del montículo que ocupa el asentamiento. Fuera del muro de circunvalación, que en este sector es doble y alcanza dimensiones de más de tres metros de altura, dos tipos de complejos arquitectónicos muy diferenciados caracterizan a este sector. Por una parte, al NE y SE, hay numerosos conjuntos de torreones de piedra, cuya planta afecta formas circulares y han sido definidos por la literatura arqueológica como chullpas. Interrumpe entre estos torreones una gran plaza rectangular ubicada en la parte central y cuyo muro oriental constituye el límite del pukara. Inmediatamente fuera de este muro oriental, corre un camino de $5 \mathrm{~m}$ de ancho cuya huella se pierde hacia el norte y el sur. Hay varias estructuras rectangulares, algunas de dos aguas, que están fuera de los muros y miran hacia el camino. Dentro de la plaza se distingue una gran edificación de adobes, de carácter estrictamente rectangular, que inscribe una superficie de más de $200 \mathrm{~m}^{2}$, tiene techo de dos aguas, sostenido por altas cumbreras con tres vanos en sus partes superiores. Esta estructura presenta, en el muro que da hacia la plaza, tres vanos de acceso. (FoTO 1)

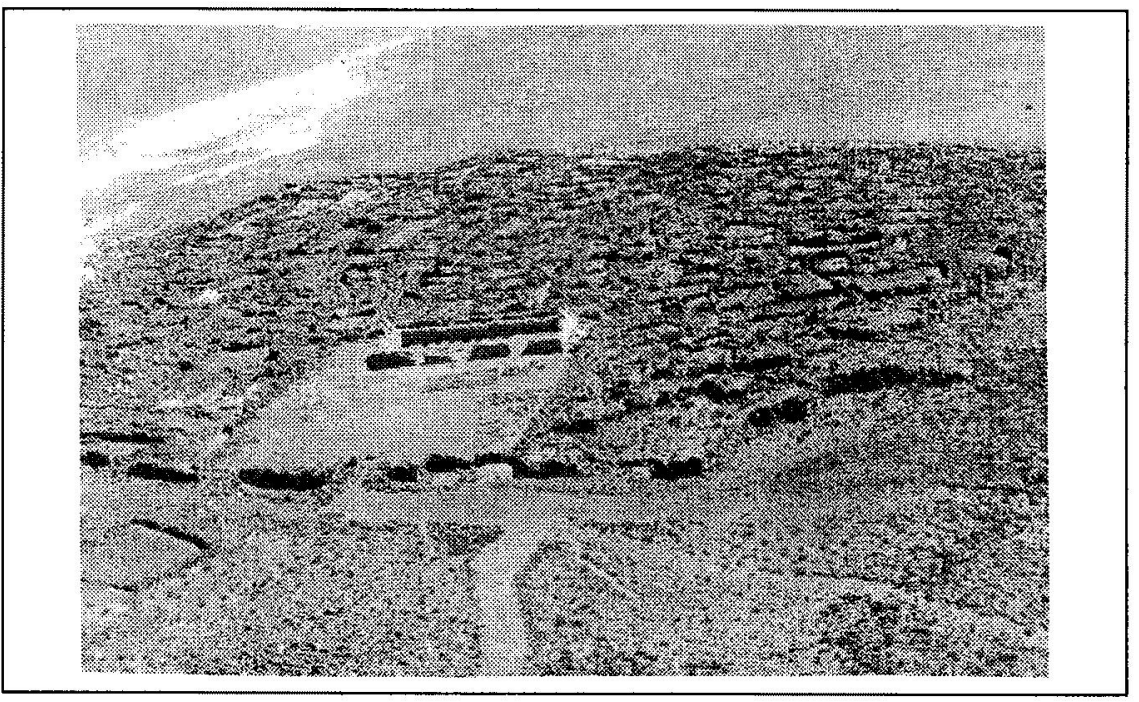

Foto 1. Vista aérea del Pukara de Turi. 
Una observación preliminar da cuenta que al menos la plaza y la edificación de adobes que inscribe, son estructuras de carácter netamente incaico, lo mismo que el camino que corre adyacente al muro exterior de la plaza y las estructuras rectangulares asociadas a él. En los inicios de nuestra investigación planteamos la hipótesis de que estas estructuras eran un testimonio del impacto que el Tawantinsuyu había dejado en el pukara de Turi ${ }^{4}$.

\section{Rituales altiplánicos.}

En el sitio Likan, ubicado en la localidad de Toconce, $20 \mathrm{~km}$ al este de Turi, encontramos una de las evidencias más tempranas de una incursión de etnias altiplánicas en Atacama durante el Período Intermedio Tardío. (LÁMINA 4) Ellas se manifiestan en las cabeceras del río Salado, afluente del Loa, en los inicios del siglo $\mathrm{X}$, mestizándose con la población local. Entre la configuración de elementos que caracterizan a este asentamiento, son especialmente relevantes para este estudio las chullpas, o torres circulares de piedra, estructuras de una edificación comparativamente muy cuidadosa, que exhiben en su interior un esmerado emplantillado de piedra a modo de piso, rasgo extraordinario para este período y región. Las chullpas siempre están agrupadas en las cotas más altas de los asentamientos pertenecientes a esta fase arqueológica, que hemos denominado Fase Toconce, y se encuentra en varios asentamientos de la Región del Loa Superior ${ }^{5}$. (FoTO 2)

Investigaciones llevadas a cabo en el sitio Likan ${ }^{6}$, demostraron que estas estructuras, que en el altiplano central exhiben una funcionalidad funeraria, no fueron utilizadas como enterratorios, sino como lugares de ofrendas rituales, vinculadas a cultos funerarios. Es especialmente significativo el hecho de que los vanos de todas estas estructuras están orientados hacia los grandes cerros y volcanes que se destacan en el

4. C. Aldu n a te et al: Cronologia y asentamiento en la región del Loa Superior, Santiago de Chile 1986.

5. C. Aldunate et al:: op. cit. 1986.

6. C. Ald u n a e et al:: Las chullpa de Toconce y su relación con el poblamiento altiplánico en el Loa Superior: Periodo Tardio, Santiago de Chile 1981. 


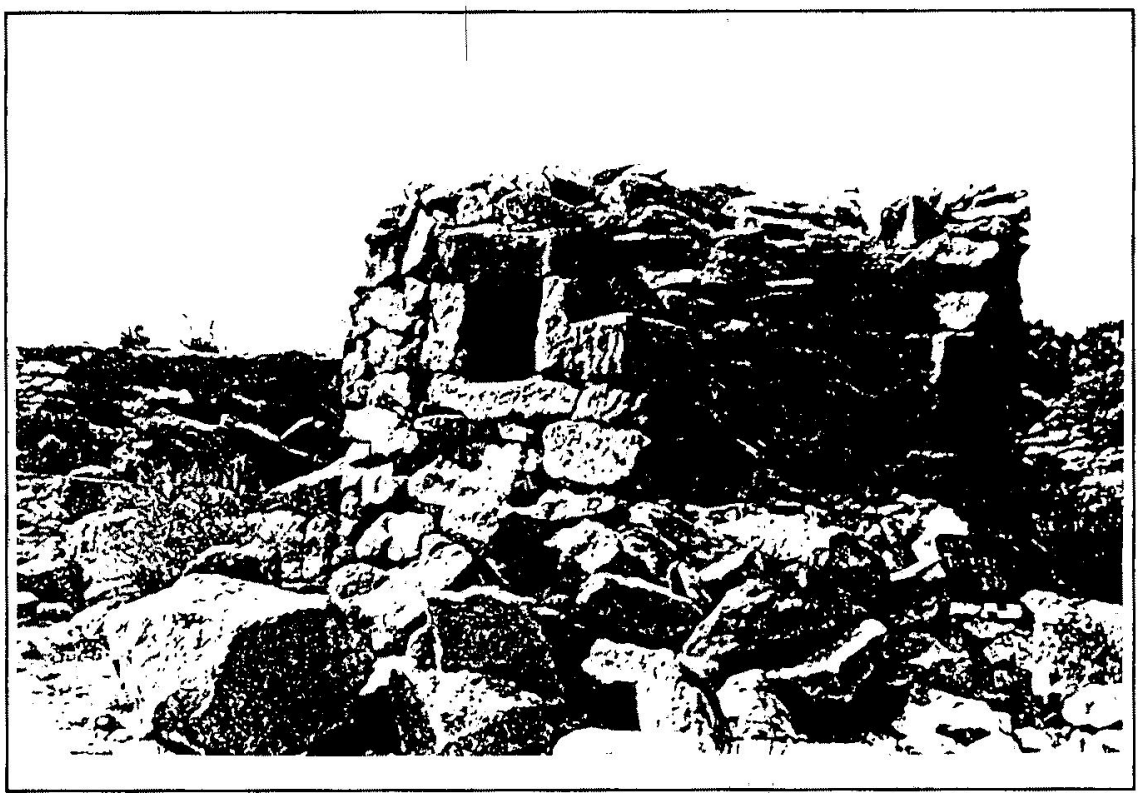

Foto 2. Chullpa del sitio Likan. Fase Toconce ca. 900-1250 d.C.

horizonte, y alrededor de la mitad de ellos se encuentra dirigida hacia un conjunto de promontorios, dentro de los que se encuentra el cerro Puma Orko o Mallku León, al que los actuales lugareños veneran y dirigen sus oraciones, pues alli habitan sus ascendientes y las divinidades, que se regocijan juntos en sus alturas ${ }^{7}$. Es conocida la ideología andina respecto a los lugares de origen de los pueblos, las achachilas, que a menudo son identificadas con las grandes protuberancias u oquedades de la tierra, jugando los cerros un rol de especial importancia. En toda esta región hemos constatado que las estructuras rituales actualmente en uso por los lugareños, como capillas, cementerios, plazas rituales y «cajitas», están orientadas hacia estos mismos cerros (ob. cit.). (LÁmina 5) (Foto 2A)

7. C. Aldunate et al.: «La función de las chulipa en Likan», en: Actas del VIII Congreso de Arqueologia Chilena, Valdivia 1982. 
DIAGRAMA DE ORIENTACION DE LOS VANOS DE CHULLPA RESPECTO DE LOS PUNTOS CARDINALES $Y$ LAS CUMBRES QUE RODEAN EL AREA.

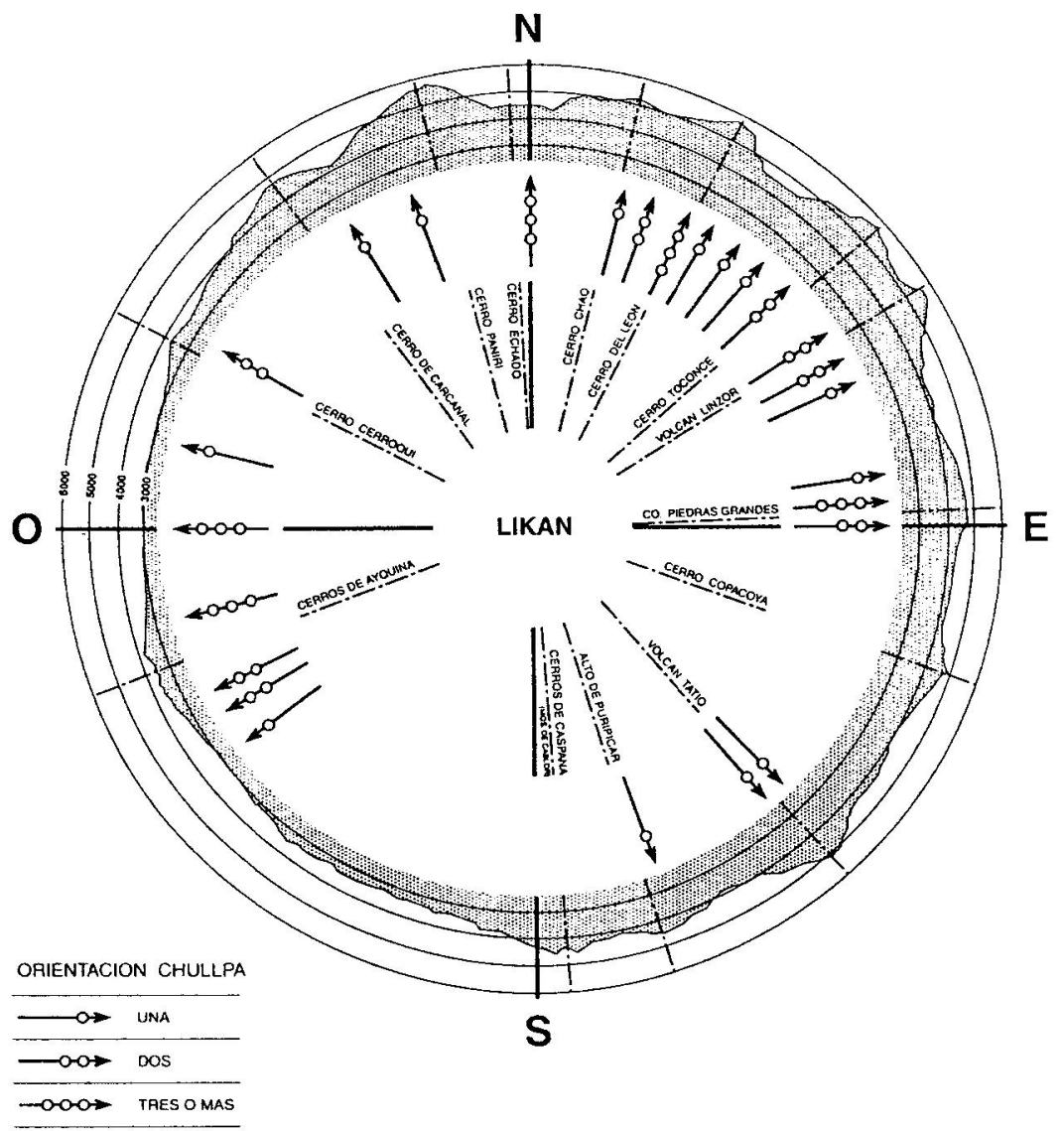


Foto 2a. Capilla del sitio

Likan (etnográfica), orientada hacia el cerro Mallku León.

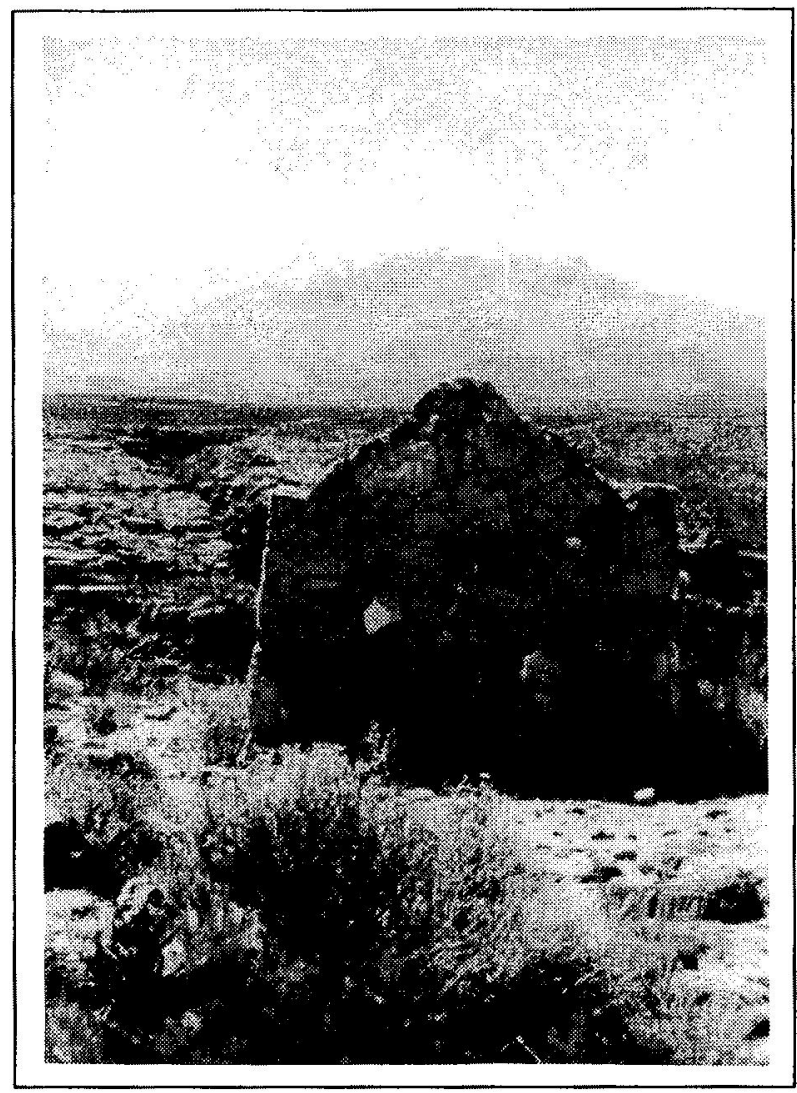

En el pukara de Turi, entrado el siglo XIV, encontramos testimonios de la llegada de la fase Toconce, que construye en la parte superior de este asentamiento un conjunto de chullpas, también orientadas hacia los cerros de la localidad, especialmente hacia el Paniri, gran volcán que los actuales habitantes del vecino pueblo de Ayquina, consideran sagrado. Las investigaciones realizadas en Turi han demostrado que estas estructuras presentan características idénticas a las de Likan en sus aspectos formales y contextuales, siendo sólo uno o dos siglos más tardías. La fechas terminales de Toconce, coinciden con las del arribo de esta fase a Turi, por lo que nuestra hipótesis es que Toconce llega a Turi durante el siglo XIV, abandonando su lugar de origen. (FoTо 3) 


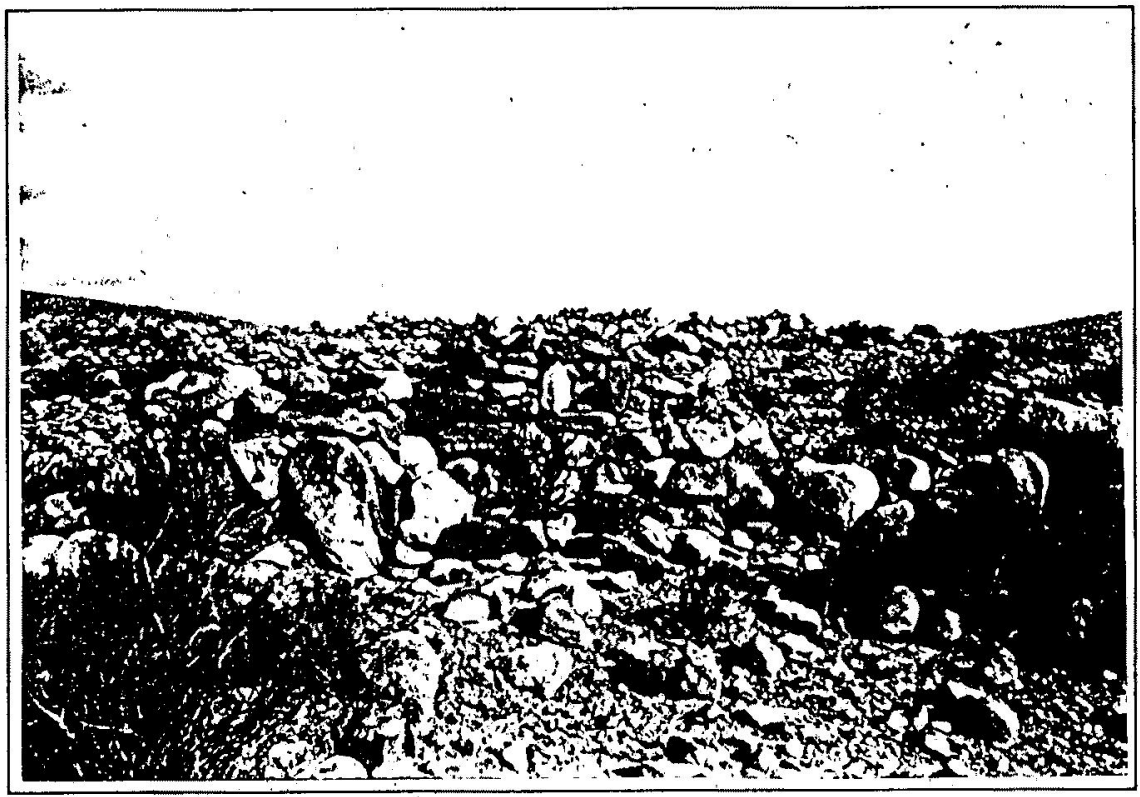

Foto 3. Chullpa del sitio Pukara de Turi. Fase Turi 2 1350-1500 d.C.

Las investigaciones también han arrojado luz sobre otras prácticas rituales altiplánicas que están asociadas a esta misma ocupación del pukara de Turi por la fase Toconce (fase Turi 2). Entre ellas, la más relevante consiste en los ritos de ofrendas, cuyos restos se entierran en lugares especialmente determinados, práctica que subsiste hasta hoy entre los lugareños, que la denominan waki.

En gran parte de las estructuras del pukara, hemos exhumado este tipo de ofrendas, que se encuentran enterradas bajo el piso de las habitaciones, dando la impresión de tratarse de waki fundacionales, hechos al construir las estructuras, tal como se acostumbra hasta hoy en muchas localidades altiplánicas ${ }^{8}$. Los elementos que se han encontrado formando parte de la ofrenda son artefactos de piedra, principalmente palas, cuchillos o raspadores y/o huesos de camélidos. 
Para el conocimiento de la religiosidad y el ritual altiplánico de esta época, uno de los waki que arrojó mayor información fue el de la estructura 166, de cuyos cimientos se exhumó un contexto de huesos de mandíbulas y metapodios de camélidos, el cual presenta una interesante configuración ideológica que consagra la dualidad andina ${ }^{9}$. Había una mitad izquierda de mandíbula de llama adulta y otra mitad derecha de guanaco joven, junto a un metacarpo izquierdo juvenil y un metatarso derecho de adulto, lo que plantea las siguientes oposiciones:

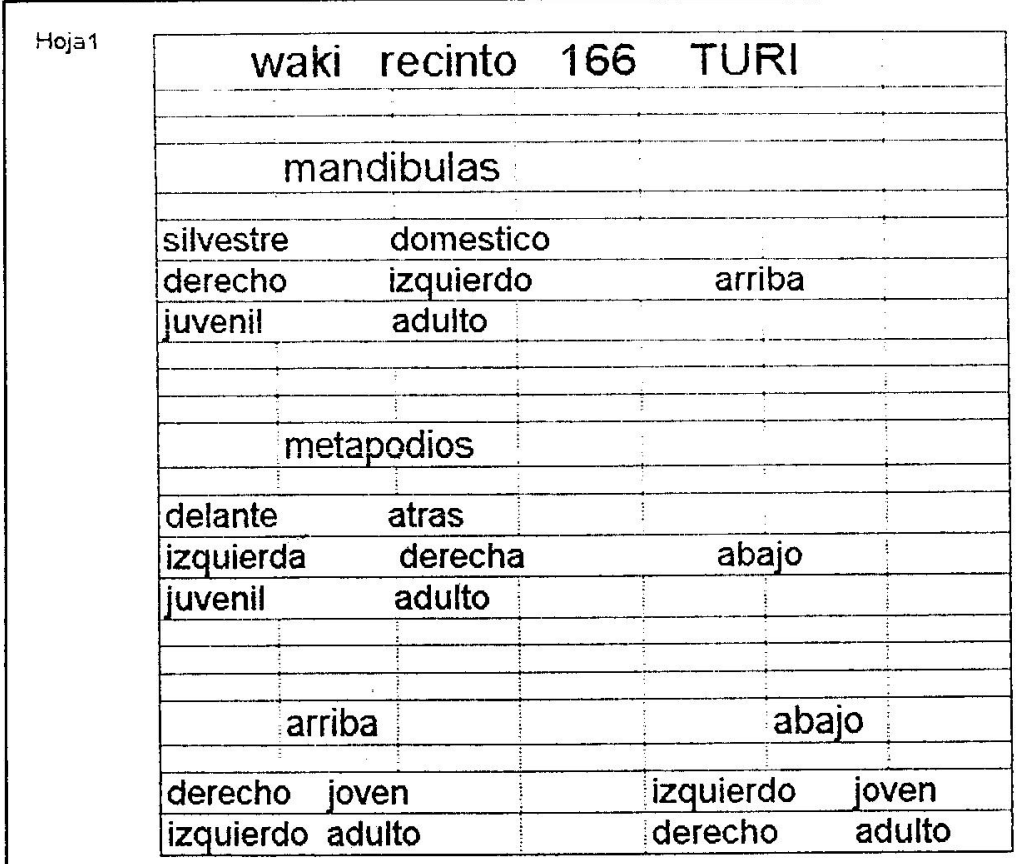

LÁMINA 6

9. Entre muchos, vid. T. $\mathrm{Zu}$ ide m a: «The Ceque System of Cuzco: the Social Organization of the Capital of the Inca», en: International Archives of Ethnography, suplemento al tomo 1, E. Brill, Holanda 1964. 


\section{Rituales incaicos.}

Los testimonios incas en el inventario artefactual mueble de Turi son casi nulos. En más de una tonelada de fragmentos cerámicos analizados en este sitio, no se ha encontrado sino una docena de fragmentos de escudillas planas ornitomorfas $y$ otras formas incaicas todas manufacturadas en el tipo cerámico local Rojo Pintado, dos fragmentos Saxamar y uno probablemente Inca Paya. En el contexto de ofrendas exhumado de una chullpa, se registraron dos piezas de cerámica de morfología inca, confeccionados en el tipo local Rojo Pintado. Invariablemente, estas evidencias incaicas estaban asociadas a cerámicas altiplánicas (Laguna Hedionda y Yavi).

Estas escasas huellas incaicas, sin embargo, no pueden acallar la presencia de una kallanka de adobes de grandes proporciones, con cimientos de piedra, siguiendo el típico modelo cuzqueño ${ }^{10}$, otras estructuras de adobes, una gran plaza rectangular, a modo de kancha y estructuras de piedra rectangulares, algunas a dos aguas, todas las que exhiben fuertes rasgos incaicos y constituyen una evidente ruptura con la arquitectura anterior del asentamiento. Ellas están hechas en la cumbre del promontorio, no dentro de la aldea amurallada, sino en su margen oriental-superior, como dándole la espalda al asentamiento y vinculadas espacialmente con un ancho camino, también de tipología inca ${ }^{11}$. Estas construcciones están hechas en un evidente gesto de separar el sector incaico del preexistente, y previamente a su construcción se preparó el terreno, nivelándolo, en oposición a la arquitectura previa, que se adaptaba a la topografía del lugar. Todos estos rasgos sugieren una fuerte presencia del Tawantinsuyu en un asentamiento local, que debe ser convenientemente explicada.

El hecho de que la plaza y kallanka hubieran sido construidas en las cotas superiores, interrumpiendo el sector donde se ubican la mayor parte de las chullpas, nos sugirió que estas estructuras incaicas fueron hechas en el lugar más sagrado de Turi, donde estaban colocadas las estructuras chulparias, siguiendo el patrón característico de la Fase Toconce. Para ello, necesariamente deberían haber sido destruidas estas 
estructuras rituales, lo que implicaría una imposición violenta del Tawantinsuyu sobre Turi. En las últimas excavaciones efectuadas al interior de la kallanka, se demostró fehacientemente que para construir esta edificación y la gran plaza anexa, se debió aplanar la cumbre del promontorio y quedaron en evidencia al menos dos pavimentos de chullpas que fueron destruidas para asentar allí estas edificaciones. La estratigrafía arquitectónica fue confirmada por la estratigráfica, pues las mismas excavaciones demostraron que para hacer los heridos de los cimientos de la kallanka, se rompió la capa de ocupación correspondiente a Turi 2 , demostrando que fue durante o después de esta época que se construyó dicha edificación. (FoTo 4)

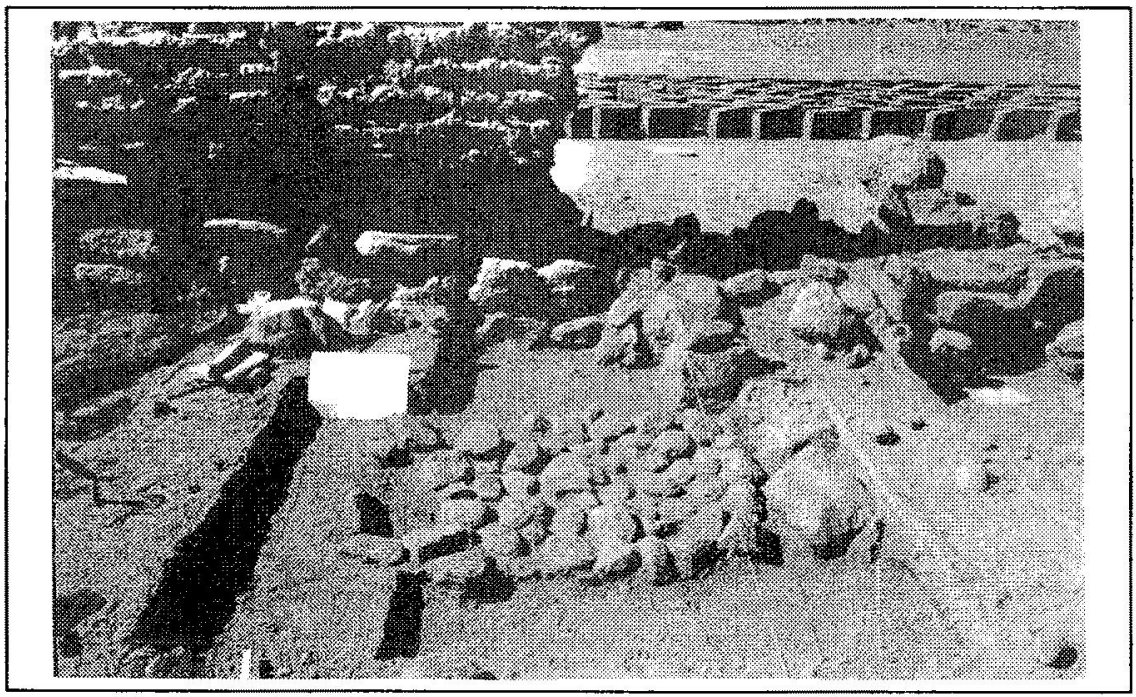

Foto 4. Emplantillado de chullpa encontrado en el interior de la kallanka.

Otro antecedente interesante obtenido en las labores de excavación y consolidación de la kallanka fue la constatación de la solidez de los cimientos de dicha construcción. A manera puramente incaica, y sin relación a la tecnología arquitectónica previa, se practicaron heridos profundos (hasta $1.5 \mathrm{~m}$ en algunos sectores), en los que se depositaron 
grandes piedras a modo de cimientos. Para asegurar los puntos críticos de la edificación, que daban estabilidad de las altas cumbreras de la kallanka, se construyeron cimientos especialmente profundos y sólidos en sus vértices. Los cimientos de piedra sobresalían algunas decenas de centímetros del nivel del suelo para que los muros de adobe no sufrieran la erosión provocada por las partículas de arena arrastradas por el viento. Todos estos cuidados evidencian el perfecto dominio de una tecnología arquitectónica compleja y especializada en grandes construcciones, extrañas en la región. Si a esto agregamos que los muros de esta edificación son de adobes, completamente exóticos para el Tardío regional, tan bien hechos que han resistido los embates de cinco siglos, no queda lugar a dudas de que estamos frente a tecnologías evidentemente foráneas.

Sin embargo de esta esmerada construcción, en uno de los vértices de la kallanka (el sureste), se descuidó deliberadamente el cimiento y en vez de asegurar este punto crítico con grandes piedras, como en los otros casos, se hizo un entierro ritual, poniendo en grave peligro la construcción y resultando en el colapso de ese sector. Este ofertorio estaba compuesto por un cráneo de un hombre joven (25-35 años), al parecer de proveniencia local, sin deformaciones artificiales ni huellas de haber sido decapitado, sugiriendo un entierro post mortem del cráneo separado del cuerpo, con pintura roja, hojas de coca y otros restos vegetales, que están siendo analizados. Esta prạ́ctica nos sugirió una analogía con los waki fundacionales del altiplano, pero con modalidades muy especiales y sugerentes. (FoTO 5)

Los antecedentes nos hacen pensar en una concesión de la tecnología foránea a las tradiciones locales, que probablemente fueron tan fuertes que obligaron a hacer esta "costumbre» altiplánica a pesar del peligro que representaba para la construcción. La trasmutación de las ofrendas tradicionales del waki por un simulacro de sacrificio humano o capacocha, podría ser una concesión local a los incas. Es muy atractivo pensar en un verdadero acuerdo entre las partes para la construcción de estas importantes estructuras. Quedaría pendiente, sin embargo, la destrucción de estructuras rituales, tan importantes como las chullpas, para nivelar el piso y construir la kallanka y la plaza en el lugar más sagrado del antiguo asentamiento, lo que sugiere más bien una fuerte imposición del Tawantinsuyu en una sociedad atacameñaaltiplánica. 
Foto 5. Excavaciones en los cimientos kallanka.

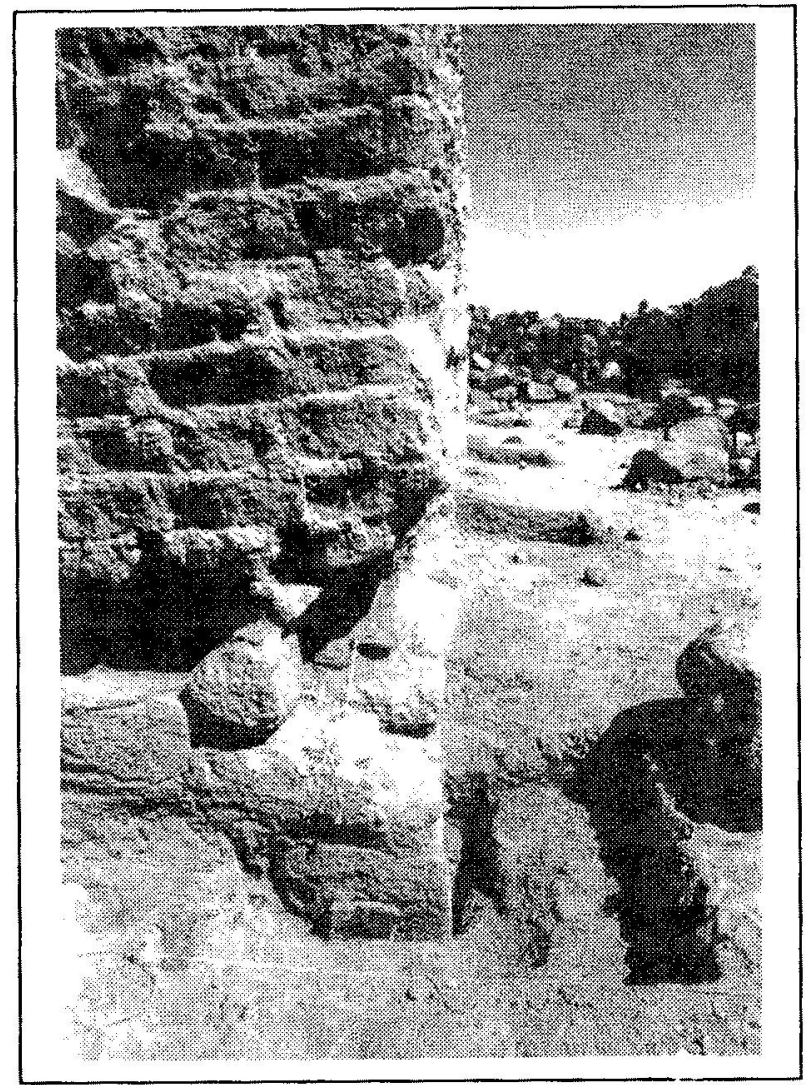

También durante el Tawantinsuyu, encontramos en nuestra región la presencia de otros rituales propios de este horizonte, que se imponen fuertemente sobre la ideología altiplánica previa. En la cumbre de los cerros de la región, hacia donde miraban los vanos de las chullpas de Likan y Turi, se encuentran restos de construcciones y otros testimonios que son característicos de los santuarios de altura incaicos. Entre estos, son importantes los hallazgos en la cima del cerro Mallku León $(5.771 \mathrm{~m})$, hacia donde miraban la mayoría de las chullpas de Likan, donde se encontraron dos plataformas y restos de leña. En la cumbre del Paniri (ca. $6.000 \mathrm{~m}$ ), cerro que enfrenta Turi y hacia donde 
se orientan muchas de sus chullpas, se encontraron nueve estructuras, acumulaciones de leña y fragmentos cerámicos incaicos ${ }^{12}$. (FOTO 6)

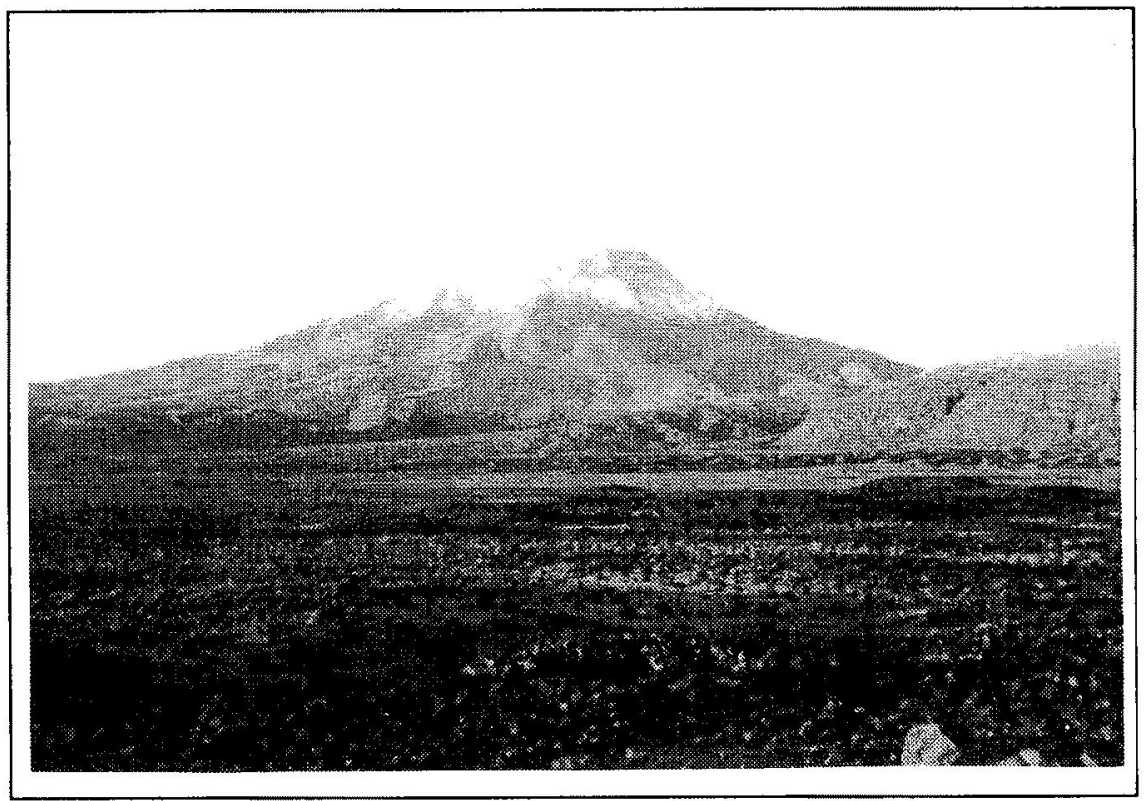

Foto 6. Volcán Paniri mirado desde Turi.

\section{Convivencias y tensiones.}

Turi nos ofrece antecedentes de importancia para evaluar los elementos ideológicos evidenciados en los rituales que dicen relación con la penetración del Tawantinsuyu en Atacama. En primer lugar, demuestra que este proceso se efectúa a través de la influencia altiplánica, que ya

12. J. Re in hard: Las montañas sagradas: un estudio etno-arqueológico de ruinas en las altas cumbres andinas, "Cuadernos de Historia», Santiago de Chile 1983; «Report on an expedition to high altitude archaeological sites in Chile and Argentina», manuscrito $A$; «A description of the structures at the summit of volcán Panirim, manuscrito B; V. Castro et al: Santuarios de altura en la subregión del Río Salado, «Chungara», número especial, X Congreso de Arqueología Chilena, Arica 1986. 
se encuentra presente en este mismo asentamiento desde mediados del siglo XIV. Un siglo más tarde y bajo estas mismas influencias, se hacen importantes alteraciones arquitectónicas de carácter cuzqueño en el pukara, las que no se presentan acompañadas de ninguna otra modificación en los contextos, con la única salvedad de escasísimas evidencias de cerámica de factura local y morfología inca. Todo esto sugiere que las influencias incaicas e incluso las construcciones de tipo cuzqueño, fueron llevadas a cabo sin alterar mayormente a esta sociedad. Deben haber sido las cabeceras altiplánicas, que recibieron un impacto más profundo del Tawantinsuyu, las que trasmitieron estos choques a los lugares que ya habían ocupado ${ }^{13}$. Los miembros de la elite de Turi $^{14}$, para legitimar su autoridad en el nuevo modelo del Tawantinsuyu, habrían construído estas nuevas edificaciones y alterado los espacios del pukara al modo cuzqueño.

En el aspecto ideológico, podemos acreditar que los rituales altiplánicos característicos de Turi 2 preincaico, subsisten durante la presencia del Tawantinsuyu en este asentamiento. Hemos detectado entierros rituales o waki fechados en plena época inca. Por otra parte, en contextos de chullpas se han encontrado ofrendas de cerámica local con características formales incaicas, demostrando la supervivencia de las ideologías y rituales altiplánicos, después de la irrupción del Tawantinsuyu en el sitio.

Sin embargo de lo establecido, el pukara es alterado profundamente. Se nivela la cumbre del promontorio, destruyendo las estructuras rituales previas para construir la plaza y kallanka. Cambia de orientación el antiguo asentamiento que miraba al oeste, donde se ubican las vegas. Las estructuras principales construidas por el Tawantinsuyu, alteran este orden y dejan el pukara orientado hacia el este y vinculado con el camino incaico. Por último, la evidente superposición de santuarios incaicos sobre los cerros sagrados, evidencian la clara intención del Tawantinsuyu de imponer nuevas condiciones ideológicas a las poblaciones de Atacama.

El establecimiento del sector de chullpas en las partes más altas de los asentamientos, característica de los sitios de la Fase Toconce y la

13. Cf. A. Llagostera: «Hipótesis sobre la expansión incaica en la vertiente occidental de los Andes meridionales», en: Homenaje al R.P. Gustavo Le Paige, Antofagasta 1976.

14. Cf. J. Hy slop: Inka Settlement Planning, Austin 1990. 
ulterior destrucción de estas estructuras en Turi para edificar en el mismo lugar la plaza y kallanka, es una demostración de la relevancia simbólica que en la arquitectura ceremonial andina tenía la diferenciación del espacio sagrado en un patrón vertical ${ }^{15}$.

De acuerdo al aspecto simbólico que se ha atribuido a la arquitectura incaica, estas nuevas condiciones seguramente tuvieron que ver con la estructura estatal Inka, que reformulaba los espacios y transformaba cada asentamiento dominado en un nuevo Cuzco, para apropiarse de ellos y establecer una clara diferenciación con otros de la misma región que no le interesaban de la misma manera ${ }^{16}$.

En estas circunstancias, Turi estaría demostrando una llegada del Tawantinsuyu a Atacama a través de las redes de influencias de jerarquía y poder establecidas previamente por las sociedades altiplánicas, bajo un fuerte tamiz de la cultura local. En este proceso, jugaron un importante papel los aspectos ideológicos andinos y especialmente los incaicos, que a veces convivieron, y en otras, el Tawantinsuyu reformuló el espacio, transformando al asentamiento y tomó posesión de los sitios sagrados, sin dejar duda de las nuevas condiciones que imponía. Un elemento que puede confirmar esta conclusión es la presencia actual de un «bolsón» de la lengua quechua entre los actuales habitantes de esta región, a pesar de su origen aymara.

15. Vid. M.E. Moseley: «The Exploration and Explanation of Early Monumental Architecture in the Andes", en: Early Ceremonial Architecture in the Andes, Washington D.C. 1985.

16. Cf. C. Mor $r$ is: «Signs of Division, Symbols of Unity: Art in the Inka Empire», en: Circa 1492: Art in the age of exploration. Washington 1991; J. Hy slop: "Factors Influencing the Transmission and Distribution of Inka Cultural Materials throughout Tawantinsuyu», en: Latin American Horizons, Washigton 1993; F. Gallardo: op. cit. MS. 